\title{
Endoscopic submucosal dissection of colorectal neoplasms: an audit of its safety and efficacy in a single tertiary centre in Singapore
}

James Weiquan $\underline{L}^{1}$, MBBS, MRCP, Tiing Leong $\underline{A n g^{1}}$, FRCPE, FAMS, Lai Mun Wang $^{2}$, MB BCh BAO, FRCPath, Andrew Boon Eu Kwek ${ }^{1}$, MBBS, MRCP, Malcolm Teck Kiang $\underline{T a n}^{1}$, MBBS, MRCP, Kwong Ming Fock ${ }^{1}$, FRCPE, FAMS,

Eng Kiong $\underline{T e O}^{1}$, FRCPE, FAMS

INTRODUCTION Endoscopic submucosal dissection (ESD) provides a higher en bloc and RO resection rate than endoscopic mucosal resection. Colorectal ESD is not widely used because of its technical difficulty and risk of complications, especially for right-sided colonic lesions. We audited the clinical outcomes of our initial experience with colorectal ESD.

METHODS We reviewed data collected from a prospective registry of patients who underwent colorectal ESD from December 2014 to March 2018. Therapeutic outcomes and procedure-related complications were analysed.

RESULTS A total of 41 patients (mean age 67.4 years, 21 male) underwent colorectal ESD. The distribution of the lesions was as follows: rectum $(n=9)$, sigmoid colon $(n=8)$, descending colon $(n=6)$, splenic flexure $(n=1)$, transverse colon $(n=5)$, ascending colon $(n=8)$ and caecum $(n=4)$. The mean size was 23 (range 12-50) mm. En bloc resection was achieved in 35 (85.4\%) out of 41 patients, and R0 resection or clear resection margins was achieved in 33 ( $94.3 \%)$ of the en bloc resection patients. The lesion was upstaged in 14 (34.1\%) patients after ESD. Colonic perforation occurred in $3(7.3 \%)$ patients during ESD and was successfully treated with endoscopic clips. There was no procedure-related bleeding. No patient required surgery for management of complications. The median duration of hospitalisation was 1 (range 0-7) day. Four patients with lesions that were upstaged after ESD, from high-grade dysplasia to intramucosal carcinoma with deep submucosal invasion, were referred for colectomy.

CONCLUSION Our early outcome data was comparable to that from large published series. ESD is an effective and feasible treatment for colorectal lesions.

Keywords: adverse effects, colorectal cancer, colorectal neoplasms, endoscopic submucosal dissection, treatment efficacy

\section{INTRODUCTION}

Gastrointestinal (Gl) cancers are among the leading causes of morbidity and mortality worldwide, ranking among the top five cancers for age-standardised incidence and mortality rates. ${ }^{(1)}$ Advances in endoscopic imaging have been shown to increase the diagnostic yield of early detection and provide more accurate diagnoses of early gastric and colorectal cancer and pre-neoplastic lesions. ${ }^{(2-6)}$ Based on data derived from histopathological correlation, early GI neoplasia has been shown to pose no or minimal risk of nodal metastasis. ${ }^{(7)}$ As a result, these neoplastic and pre-neoplastic lesions are amenable to curative resection by means of endoscopic therapy, decreasing the morbidity associated with major surgery.

Although many cases of superficial GI neoplasia may be treated by simple polypectomy or endoscopic mucosal resection (EMR), these techniques may be inadequate in some instances. Examples include flat lesions that are larger than $20 \mathrm{~mm}$ or those which do not lift adequately during submucosal injection. In these cases, endoscopic submucosal dissection (ESD) may be utilised to overcome the limitations associated with EMR. Moreover, ESD has been shown in several large series to be associated with high en bloc and $\mathrm{R} 0$ resection rates ranging from $95.3 \%$ to $97.1 \%$ and $84.9 \%$ to $87.7 \%$, respectively, for gastric lesions, ${ }^{(10,11)}$ and $88 \%$ to $98.3 \%$ and $88.6 \%$ to $89 \%$, respectively, for colorectal lesions. ${ }^{(11,12)}$ Meta-analyses comparing ESD and EMR have shown that ESD produces higher en bloc and R0 resection rates for both gastric ${ }^{(13)}$ and colorectal ${ }^{(14)}$ lesions.

ESD is more technically challenging than EMR. Most superficial tumours in the colorectum tend to be benign adenomatous lesions. ${ }^{(15,16)}$ As such, EMR is successful in approximately $95 \%$ of colorectal lesions, and removal by standard polypectomy or EMR is recommended. ${ }^{(17)}$ However, conventional snare techniques are inadequate for flat or sessile lesions larger than 15-20 mm that have morphological characteristics suggestive of high-grade dysplasia (HGD) and intramucosal cancer (IMC). In these cases, colorectal ESD allows a higher chance of curative resection and accurate histopathological analysis of the resection depth and margins.

While this technique is increasingly being used, technical challenges and lack of experience may lead to an inability to achieve results, as reported in the literature. Moreover, the rate of perforation is estimated to be $4.8 \%{ }^{(18)}$ which is higher than that for EMR, and rates as high as $12 \%$ have been reported from smaller-volume centres. ${ }^{(12)}$ Delayed bleeding rates of up to $13.9 \%$ have also been reported, although this can be controlled endoscopically in most cases. ${ }^{(19)}$ The steep learning

${ }^{1}$ Department of Gastroenterology and Hepatology, ${ }^{2}$ Department of Laboratory Medicine, Changi General Hospital, Singapore

Correspondence: Prof Ang Tiing Leong, Chief and Senior Consultant, Department of Gastroenterology and Hepatology, Changi General Hospital, 2 Simei Street 3, Singapore 529889. ang.tiing.leong@singhealth.com.sg 
curve, alongside high complication rates that arise with lack of experience, may render this technique prohibitive despite its many advantages and even its necessity in certain situations.

Most of the published data currently available on colorectal ESD is from referral centres in Japan. Even in Japan, this procedure was only covered by health insurance recently, in April 2012. There is a paucity of data regarding the safety and efficacy of colorectal ESD outside of East Asia. Colorectal ESD is not widely used because of its technical difficulty and risk of complications, especially for right-sided colonic lesions. Hence, we audited the clinical outcome of our initial experience in colorectal ESD, focusing on its safety and efficacy.

\section{METHODS}

This was a retrospective single-centre audit conducted at Changi General Hospital, a regional hospital located in the eastern part of Singapore. A prospective registry of all cases undergoing colonic ESD had been set up since the introduction of this technique into clinical service in December 2014, for audit and quality assurance purposes. The captured data included demographics, site and size of colorectal lesion, type of device used, whether en bloc and R0 resection were achieved, and complications arising from the procedure. Cases that were documented from December 2014 to March 2018 were audited. In addition, the initial biopsy results (when available), were compared with the final histology from the resected specimen to evaluate the number of lesions that were upstaged post ESD. All patients provided informed consent prior to the procedure and consented to the use of anonymised data for audit and academic purposes.

Colonic ESD was performed under endoscopist-administered intravenous sedation (midazolam, with or without fentanyl) in the endoscopy centre. All patients underwent a full colonic bowel preparation with split-dose polyethylene glycol prior to endoscopy. Endoscopy was performed using a therapeutic gastroscope for left-sided lesions and a colonoscope for right-sided lesions. For ESD, the margins of the lesion were first elevated by a submucosal injection of either saline or hypromellose solution mixed with indigo carmine, followed by circumferential incision. Thereafter, the lesion was elevated by a submucosal injection of hypromellose solution mixed with indigo carmine, followed by submucosal dissection.

The colonic electrosurgical knives used were either needle-type knives (DualKnife ${ }^{\mathrm{TM}}$ with $1.5 \mathrm{~mm}$ cutting knife length [Olympus, Tokyo, Japan]; FlushKnive ${ }^{\mathrm{TM}}$ with $1 \mathrm{~mm}$ cutting knife length [Fujifilm, Tokyo, Japan]) or scissors-type knives (ClutchCutter ${ }^{\mathrm{TM}}$ with $3.5 \mathrm{~mm}$ knife length [Fujifilm, Tokyo, Japan] or SB Knife ${ }^{\mathrm{TM}}$ Jr with $3.5 \mathrm{~mm}$ knife length [Sumitomo Bakelite, Tokyo, Japan]). In scissors-type knives, the cutting mechanism is based on grasping the mucosa and pulling it while applying electrocautery, unlike the needle-type knives that cut by forward and lateral pressure while applying electrocautery. Thus, the process is technically easier with the scissors-type knives, which were used for all right-sided lesions.

Visible vessels within the submucosa were coagulated prophylactically. Any periprocedural bleeding was arrested with the use of haemostatic forceps applying coagulation current. Any perforation that occurred during ESD was closed with endoscopic clips. ESD procedures in our series were performed by both trained personnel (Ang TL) and trainees (Kwek ABE, Tan MTK and Li JW) under direct supervision, with the trainer taking over the endoscope whenever difficulties were encountered by the trainees.

Successful en bloc resection was defined as successful resection of the lesion in a single piece macroscopically. Piecemeal resection referred to resection of lesion that was achieved in multiple fragmented pieces. R0 margin status for invasive carcinoma on resection specimen was defined as complete clearance of peripheral and deep (cauterised base) margins by at least $1 \mathrm{~mm}$ on histologic assessment. In non-cancer cases, the term 'clear resection margins' was used. Immediate complication referred to complications that occurred during the procedure. Minor bleeding that occurred during the process of ESD and was easily stopped was regarded as part of the process and not a complication. Severe bleeding occurring during the procedure that resulted in haemodynamic changes, needed blood transfusion or could not be secured endoscopically was considered a procedure-related complication. Delayed complications referred to complications occurring after and up to 30 days after the procedure; this included delayed bleeding even if there was no haemodynamic instability, need for transfusion or need for treatment. Colorectal neoplasms were considered to have undergone curative endoscopic resection if there was complete resection of dysplasia based on histologic and/or endoscopic assessment. In the context of completely resected IMC, the assessment of curative endoscopic resection was based on histologic criteria with negative peripheral and deep (R0) resection margin status; submucosal invasion depth of less than 1,000 $\mu \mathrm{m}$; absence of lymphovascular invasion; lack of poor differentiation; and absence of tumour budding at the invasive front. ${ }^{(8)}$

The primary outcome measures were successful en bloc resection, successful R0 resection or clear resection margins, and procedure-related complications. Secondary outcome measures were the proportion of cases upstaged after endoscopic resection and proportion of cases that required salvage colectomy due to non-curative endoscopic resection. All statistical analysis was performed using SPSS Statistics for Windows version 19.0 (IBM Corp, Armonk, NY, USA). All authors had access to the study data and approved the final manuscript.

\section{RESULTS}

During the audit period from December 2014 to March 2018, a total of 41 patients underwent colorectal ESD. Their mean age was $67.4 \pm 8.9$ years and the gender distribution was similar. The mean size of the lesions resected was 23 (range 12-50) mm. All patients had an American Society of Anesthesiologists (ASA) physical status of 1 or 2 . These findings are summarised in Table I. Among the 41 lesions, 17 (41.5\%) were right-sided (Fig. 1). Scissors-type electrocautery devices were used in a majority of the cases ( $\mathrm{n}=28,68.3 \%$ ), while needle-type electrosurgical knives were used in $8(19.5 \%)$ patients. In the remaining patients, lesions were resected with a combination of these devices. 
Table I. Characteristics of the study population and colorectal lesions $(n=41)$.

\begin{tabular}{|ll|}
\hline Parameter & No. (\%) \\
\hline Age* (yr) & $67.4 \pm 8.9$ \\
\hline Gender & $21(51.2)$ \\
\hline Male & $20(48.8)$ \\
\hline Female & \\
\hline ASA status & $13(31.7)$ \\
\hline Class 1 & $28(68.3)$ \\
\hline Class 2 & $23(12-50)$ \\
\hline Lesion size ${ }^{\text {(mm) }}$ & \\
\hline Lesion location & $9(22.0)$ \\
\hline Rectum & $8(19.5)$ \\
\hline Sigmoid colon & $6(14.6)$ \\
\hline Descending colon & $1(2.4)$ \\
\hline Splenic flexure & $5(12.2)$ \\
\hline Transverse colon & $8(19.5)$ \\
\hline Ascending colon & $4(9.8)$ \\
\hline Caecum & \\
\hline
\end{tabular}

*Data presented as mean \pm standard deviation. + Data presented as mean (range). ASA: American Society of Anesthesiologists

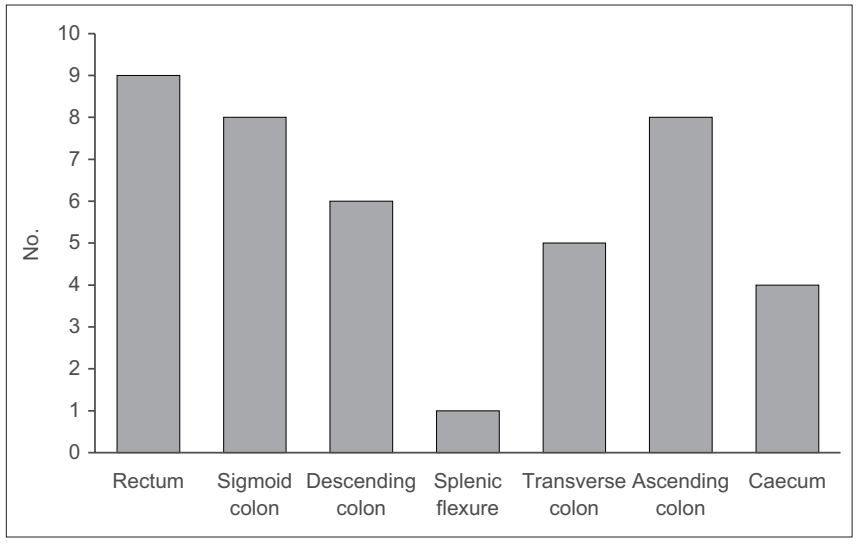

Fig. 1 Bar chart shows the distribution of colorectal lesions in the patients.

In terms of therapeutic outcomes, en bloc resection (Fig. 2) was achieved in 35 (85.4\%) patients. In addition, 33 (94.3\%) of the patients who had en bloc resection achieved $\mathrm{R} 0$ resection or clear resection margins after histopathological analysis. The remaining two cases did not have clear resection margins; these were cases of IMC with deep submucosal invasion $1.9 \mathrm{~mm}$ and $2.5 \mathrm{~mm}$ ), in which tumour cells extended to the base margin of the resected specimen. The six cases that did not achieve en bloc resection were adenomas with low-grade dysplasia (LGD). Successful piecemeal EMR with complete endoscopic resection of the adenomas was achieved in five of these patients, and the remaining one patient with rectal tubulovillous adenoma was treated with transanal surgical resection. The median total procedure time was 89 (range 35-245) minutes. This included the time taken for repeat diagnostic evaluation and teaching a trainee as well as the ESD procedure time; as this was a retrospective audit, the actual ESD time could not be accurately captured.
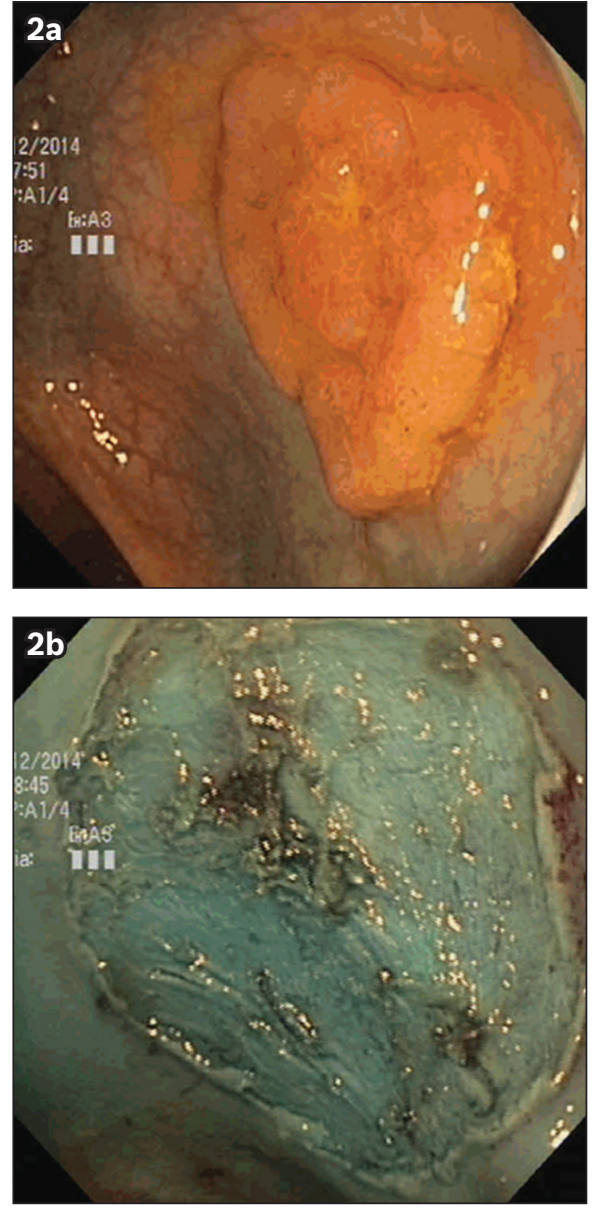

Fig. 2 Photographs show endoscopic view of a 30-mm rectal lateralspreading tumour (a) before and (b) after endoscopic submucosal dissection. Initial biopsies showed low-grade dysplasia, but post-resection histology revealed high-grade dysplasia.

There were a total of five cases of IMC in our study, all of which achieved en bloc resection with colorectal ESD. The aforementioned two patients who had tumour cells at the base margin of the resected specimen were classified as having R1 (as opposed to R0) resection. Two other patients with R0 resection did not meet the histological criteria for cure due to deep submucosal invasion exceeding 1,000 $\mu \mathrm{m}$. The remaining patient with R0 resection was deemed to have endoscopic curative resection after histological analysis of the resected specimen. The four cases that did not meet the histological criteria for cure due to inadequate margins or deep submucosal invasion were referred for surgical resection. Three patients underwent surgery, with no evidence of residual disease following ESD. In addition, the regional lymph nodes of these patients were all negative for malignancy. One patient who had IMC with $1.9 \mathrm{~mm}$ invasion into the submucosa declined surgery and was followed up for disease recurrence. This translated into an overall endoscopic curative rate of $95.1 \%(n=39)$ in our series. The results are summarised in Tables II and III.

Upstaging of histological severity from the initial biopsy results occurred in 14 (34.1\%) patients after ESD, with nine cases upstaged from LGD to HGD (Fig. 3) and five cases from HGD to IMC. Among these five patients who had adenocarcinoma diagnosed on final histology, four were referred for surgical 
Table II. Overall therapeutic outcomes and complication rates of colorectal endoscopic submucosal dissection $(n=41)$.

\begin{tabular}{|ll|}
\hline Overall outcome & No. (\%) \\
\hline Efficacy & \\
\hline Endoscopic en bloc resection & $35(85.4)$ \\
\hline Endoscopic curative resection & $39(95.1)$ \\
\hline Complication & \\
\hline Perforation & $3(7.3)$ \\
\hline Bleeding & $0(0)$ \\
\hline
\end{tabular}

Table III. Therapeutic outcomes according to histology.

\begin{tabular}{|lc|}
\hline Outcome by histology & No. (\%) \\
\hline Intramucosal cancer $(\mathbf{n}=\mathbf{5})$ & $5(100.0)$ \\
\hline Endoscopic en bloc resection & $3(60.0)$ \\
\hline R0 resection & $1(20.0)$ \\
\hline Endoscopic curative resection & $4(80.0)$ \\
\hline \multicolumn{2}{|l|}{ After endoscopic submucosal dissection } \\
\hline \multicolumn{2}{|l|}{ After examination of surgically resected specimen } \\
\hline Endosplasia and neuroendocrine tumour $\mathbf{( n = 3 6 )}$ \\
\hline Endoscopic curative resection & $30(83.3)$ \\
\hline
\end{tabular}

* Six cases without en bloc resection were low-grade dysplasia, five of which achieved complete resection by endoscopic mucosal resection.

resection, as the depth of invasion into the submucosa exceeded $1,000 \mu \mathrm{m}$ (Fig. 4), and three patients eventually underwent surgery with no evidence of residual disease or lymph node involvement on final histology. The remaining patient with IMC was deemed to have curative resection (Fig. 5).

Perforation was the only complication noted in our study and occurred in $3(7.3 \%)$ patients at the ascending colon, transverse colon and sigmoid colon. None of the patients who had a perforation required emergency surgery. One of these perforations was closed using an over-the-scope clip, while the other two perforations were successfully treated with regular endoscopic clips. A trainee was involved in two of the cases, while the third case was handled by experienced personnel. No procedure-related bleeding occurred in our study (Table II). The median length of stay was 1 (range 0-7) day. The patient who was admitted for seven days had a difficult ESD due to extensive fibrosis secondary to tattooing adjacent to the lesion by the referring endoscopist, resulting in a contained perforation that required endoscopic therapy.

\section{DISCUSSION}

ESD is a technically challenging procedure, particularly in the colon. This is in part because it is relatively novel compared to gastric ESD, and the colonic wall is also thinner than in the stomach. An overwhelming majority of the published literature on colorectal ESD originates from Japan, with very few studies coming from Western countries. ${ }^{(20)}$ Due to the lower prevalence of early gastric cancer in countries outside East Asia, endoscopists in other parts of the world may not have the volume of cases required to hone their ESD skills on gastric lesions. It is hence even more
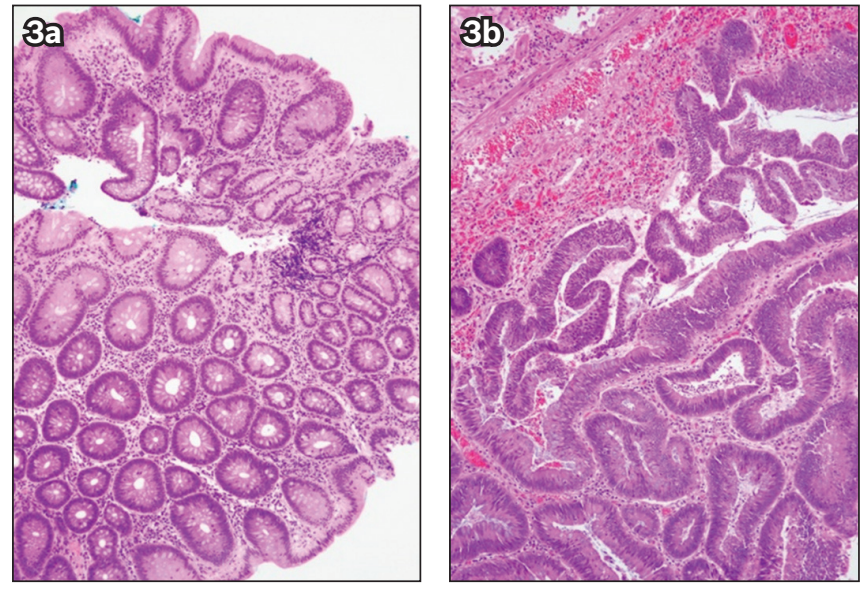

Fig. 3 (a) Photomicrograph of the initial biopsy of a caecal polyp shows tubular adenoma with low-grade dysplasia (Haematoxylin \& eosin, $\times$ 100). (b) Photomicrograph of the subsequent endoscopic mucosal resection specimen shows an increase in gland architecture complexity and nuclear cytological grade in the excised tubulovillous adenoma, consistent with high-grade dysplasia (Haematoxylin \& eosin, × 100).

difficult to embark on colorectal ESD, with its inherently higher perforation rate, longer procedure time and higher technical demands, a point that was recognised in a recent article by Rex. ${ }^{(21)}$

In our initial experience with colorectal ESD, as described in this study, our early clinical outcome data was comparable with that reported in other studies. In a recent meta-analysis by Akintoye et $\mathrm{al}^{(20)}$ that considered $\mathrm{R} 0$ resection as the primary endpoint, the pooled estimate for the R0 resection rate was $83 \%$, which was consistent with the $\mathrm{R} 0$ resection or clear resection margin rate of $80.5 \%$ ( $n=33$ ) in our study. Moreover, perforations were the main complication reported in the meta-analysis, which was also in keeping with our experience of three perforations in patients undergoing colorectal ESD, with no cases of major bleeding.

Despite its technical demands and potentially higher complication rates, colorectal ESD offers several advantages over EMR, including a lower short-term recurrence rate. ${ }^{(14,22,23)}$ Our results showed an en bloc resection rate of $85.4 \%$ and, more importantly, a high R0 and curative resection rate for colorectal lesions. An intact specimen from en bloc resection allows the pathologist to comment with confidence on the margins of resection, as shown in the patient with IMC in our study who fulfilled the criteria for curative resection and avoided the need for surgery. Although two patients with IMC achieved R0 resection, they had deep submucosal invasion exceeding $1,000 \mu \mathrm{m}$, a predictive factor for higher risk of nodal metastases, and were referred for surgery. All patients who underwent surgery did not have any evidence of residual disease, and their regional lymph nodes were also negative. If EMR had been performed, the histologic assessment of the invasion depth and peripheral margins would have been compromised due to the difficulty in orientating the fragments from piecemeal resection. Suboptimal analysis of the histologic criteria for endoscopic cure, due to the fragmented nature of piecemeal resection, is likely to result in higher referral rates for surgery. As seen in our series, the histology of post-resection specimens can be upstaged in severity from the initial biopsies; having en bloc resection specimens would allow full assessment of clearance of 

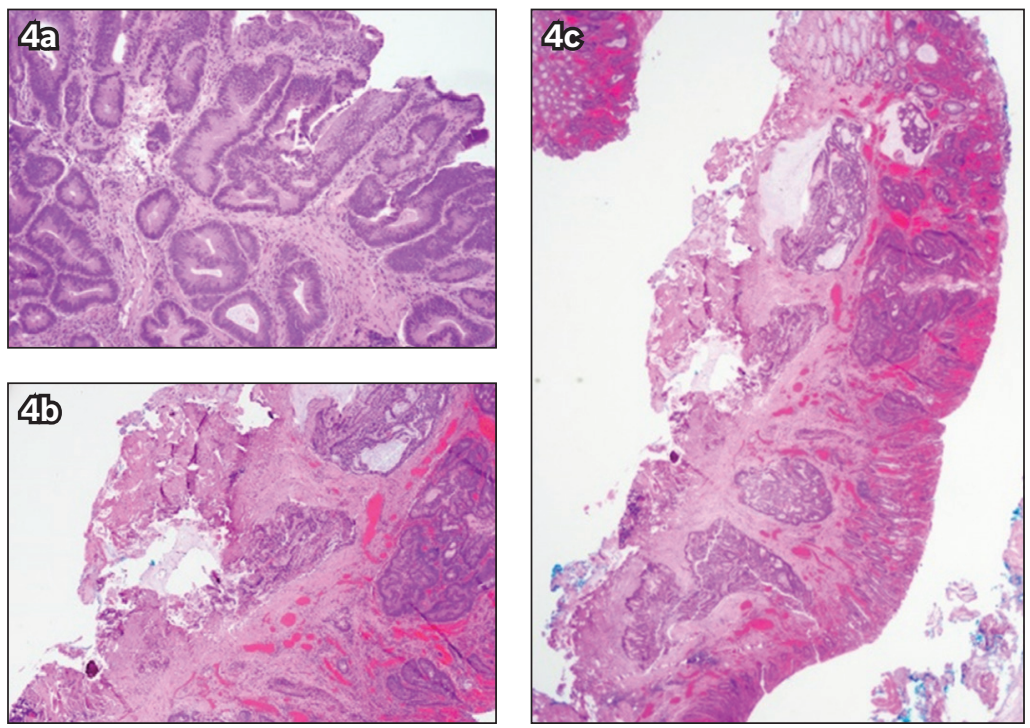

Fig. 4 (a) Photomicrograph of a biopsy specimen from a sigmoid lesion shows high-grade dysplasia within the tubulovillous adenoma (Haematoxylin \& eosin, $\times 100$ ). (b \& c) Photomicrographs of an endoscopic submucosal dissection specimen section show (b) invasive adenocarcinoma, moderately differentiated, with submucosal invasion (Haematoxylin \& eosin, $\times 20$ ); and (c) tumour cells and mucin present at the cauterised base margin of the specimen (Haematoxylin \& eosin, $\times$ 40).
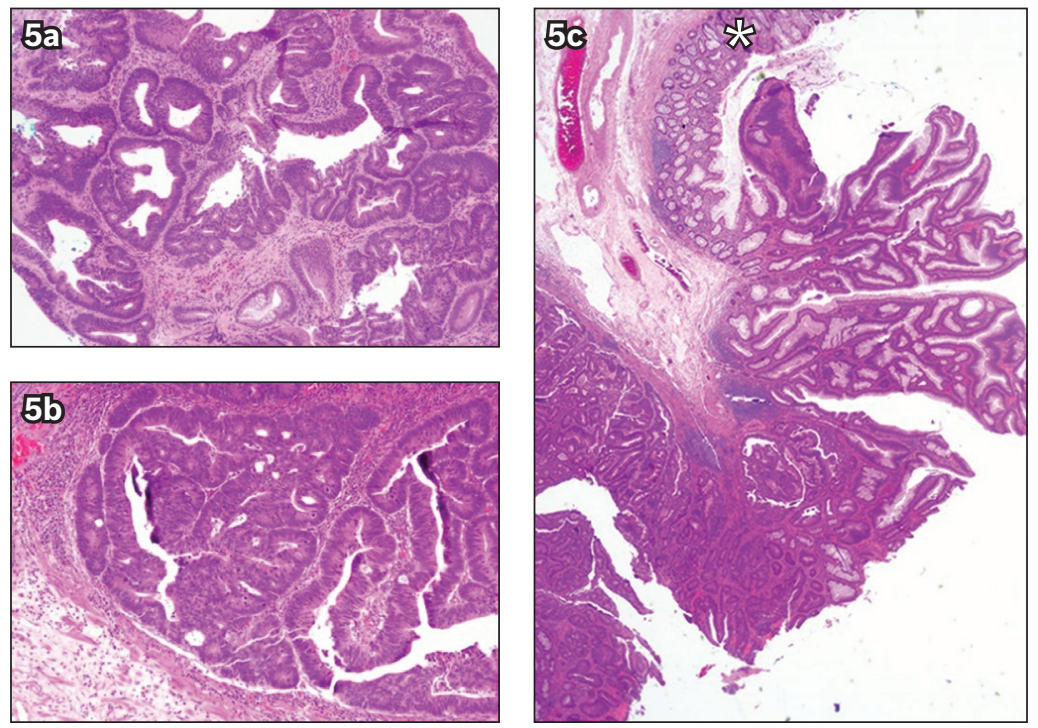

Fig. 5 (a) Photomicrograph of a biopsy specimen from a rectal polyp shows a portion of a tubulovillous adenoma with high-grade dysplasia (Haematoxylin \& eosin, $\times 100$ ). Photomicrographs of an endoscopic submucosal dissection specimen at higher magnification show (b) intramucosal carcinoma with lamina propria invasion only (Haematoxylin \& eosin, × 100); and (c) non-dysplastic large bowel mucosa (*) (Haematoxylin \& eosin, $\times 20$ ) at the periphery of a lesion that is completely resected.

margins, which is crucial in cases where lesions are unexpectedly upstaged from LGD to HGD or IMC.

The perforation rate was $7.3 \%$ in the present study, in contrast to reported rates of approximately $5 \%$ in large series. ${ }^{(20,24)}$ The higher percentage obtained could be due to our relatively small sample size and therefore smaller denominator. In addition, one of the patients had perforation due to inappropriate tattooing adjacent to the base of the lesion, resulting in submucosal fibrosis, an inability to lift the lesion for dissection and a contained perforation. However, it is also important to note that all cases of perforation were identified immediately and treated with endoscopic clips. No patients in our study required surgery for perforations. There were no bleeding complications, consistent with the low bleeding rates reported in the literature. ${ }^{(20)}$
Several studies have reported a steep learning curve for colorectal ESD. ${ }^{(25,26)}$ It is evident that hands-on experience is invaluable in order to appreciate the finer points of this technique, and these may be missed if only models are used for ESD training. ${ }^{(27)}$ However, with relatively small numbers of gastric ESD cases in centres outside East Asia, the endoscopist embarking on colorectal ESD may face an even steeper learning curve. ESD devices that were initially available in the market were needle-type devices that cut the mucosa and submucosa using the tip, which protrudes at varying lengths from the sheath depending on its design and may have adjustable knife lengths in some cases. The concern with these devices, particularly for endoscopists inexperienced with ESD, is that the tip of the knife may inadvertently penetrate deeper into the tissue layers during 
ESD, such as due to peristalsis or when the plane of dissection is not clearly seen at certain angles, resulting in a perforation. There is also a significant learning curve to achieve mastery of these types of ESD devices, especially for colorectal ESD. Two scissor-type electrosurgical knives are now available: the ClutchCutter $^{\mathrm{TM}}$ with $3.5 \mathrm{~mm}$ knife length (Fujifilm, Tokyo, Japan) and SB Knife ${ }^{\mathrm{TM}}$ Jr with $3.5 \mathrm{~mm}$ knife length (Sumitomo Bakelite, Tokyo, Japan). They are easy to operate, even for endoscopists with little experience in colorectal ESD, and are effective in difficult locations where the approach is tangential to the axis of the endoscope. ${ }^{(28-30)}$ This is due to the fact that scissors-type devices resemble biopsy or coagulation forceps, instruments that all endoscopists use routinely. The mucosal surface or submucosa is grasped in the same way that a lesion of interest is targeted using biopsy forceps, with the assistant adjusting the position of the jaws of the scissors-type device according to the clock face, similar to how the jaws of haemostasis clips are rotated prior to deployment. The endoscopist performing the ESD can check the screen to ensure that only the layer intended has been caught by the scissors-type device before applying a cutting current for dissection. The ability to manipulate the clock-face position of the scissors-type device and check the layer of interest before dissection are two major advantages of these devices, especially for lesions in more difficult positions or when tackling the proximal end of large colorectal lesions, where visibility may be obscured at certain points during ESD. The majority of cases of colorectal ESD in our series were performed using scissors-type ESD devices; this, together with adequate supervision and proper training, may arguably help overcome the learning curve associated with colorectal ESD. Indeed, the ESD procedures in our series were performed by both trained personnel and trainees under supervision.

The main limitations of our study were the small sample size and its retrospective nature. However, this study is still important, as it reports our early experience with colorectal ESD and, to the best of our knowledge, is the first such publication in Singapore and Southeast Asia. This gives us local data to support our practice and figures with which we can counsel patients, and forms the basis for further studies on this topic. Although this was a retrospective study, the data analysed had been prospectively collected and maintained in a registry.

To conclude, colorectal ESD is an effective and feasible treatment for colorectal lesions in our clinical setting in Singapore. Our early outcome data is comparable to that from large published series.

\section{REFERENCES}

1. International Agency for Research on Cancer. GLOBOCAN 2012 Estimated Cancer Incidence, Mortality and Prevalence Worldwide in 2012. Available at: http://publications.iarc.fr/Databases/larc-Cancerbases/ GLOBOCAN-2012-Estimated-Cancer-Incidence-Mortality-And-PrevalenceWorldwide-In-2012-V1.0-2012. Accessed January 25, 2019.

2. Yao K. The endoscopic diagnosis of early gastric cancer. Ann Gastroenterol 2013; 26:11-22.

3. Kaise $M$, Kato $M$, Urashima $M$, et al. Magnifying endoscopy combined with narrow-band imaging for differential diagnosis of superficial depressed gastric lesions. Endoscopy 2009; 41:310-5.

4. Yao K, Anagnostopoulos GK, Ragunath K. Magnifying endoscopy for diagnosing and delineating early gastric cancer. Endoscopy 2009; 41:462-7.

5. McGill SK, Evangelou E, loannidis JP, Soetikno RM, Kaltenbach T. Narrow band imaging to differentiate neoplastic and non-neoplastic colorectal polyps in real time: a meta-analysis of diagnostic operating characteristics. Gut 2013; 62:1704-13

6. Sano $\mathrm{Y}$, Tanaka $\mathrm{S}$, Kudo $\mathrm{SE}$, et al. Narrow-band imaging (NBI) magnifying endoscopic classification of colorectal tumors proposed by the Japan NBI Expert Team. Dig Endosc 2016; 28:526-33.

7. Gotoda T, Yanagisawa A, Sasako M, et al. Incidence of lymph node metastasis from early gastric cancer: estimation with a large number of cases at two large centers. Gastric Cancer 2000; 3:219-25.

8. Watanabe T, Itabashi M, Shimada Y, et al. Japanese Society for Cancer of the Colon and Rectum (JSCCR) Guidelines 2014 for treatment of colorectal cancer. Int J Clin Oncol 2015; 20:207-39.

9. Saitoh $Y$, Inaba $Y$, Sasaki T, et al. Management of colorectal T1 carcinoma treated by endoscopic resection. Dig Endosc 2016; 28:324-9.

10. Chung IK, Lee JH, Lee SH, et al. Therapeutic outcomes in 1000 cases of endoscopic submucosal dissection for early gastric neoplasms: Korean ESD Study Group multicenter study. Gastrointest Endosc 2009; 69:1228-35.

11. Toyonaga T, Man-i M, East JE, et al. 1,635 endoscopic submucosal dissection cases in the esophagus, stomach and colorectum: complication rates and long-term outcomes. Surg Endosc 2013; 27:1000-8.

12. Saito Y, Uraoka T, Yamaguchi Y, et al. A prospective, multicenter study of 1111 colorectal endoscopic submucosal dissections (with video). Gastrointest Endosc 2010; 72:1217-25.

13. Facciorusso A, Antonino M, Di Maso M, Muscatiello N. Endoscopic submucosal dissection vs endoscopic mucosal resection for early gastric cancer: a meta-analysis. World J Gastrointest Endosc 2014; 6:555-63.

14. Arezzo A, Passera R, Marchese N, et al. Systematic review and meta-analysis of endoscopic submucosal dissection vs endoscopic mucosal resection for colorectal lesions. United European Gastroenterol J 2016; 4:18-29.

15. Tanaka S, Oka S, Kaneko I, et al. Endoscopic submucosal dissection for colorectal neoplasia: possibility of standardization. Gastrointest Endosc 2007; 66:100-7.

16. Tanaka S, Oka S, Chayama K. Colorectal endoscopic submucosal dissection: present status and future perspective, including its differentiation from endoscopic mucosal resection. J Gastroenterol 2008; 43:641-51.

17. Pimentel-Nunes $P$, Dinis-Ribeiro M, Ponchon T, et al. Endoscopic submucosal dissection: European Society of Gastrointestinal Endoscopy (ESGE) Guideline. Endoscopy 2015; 47:829-54.

18. Oka S, Tanaka S, Kanao H, et al. Current status in the occurrence of postoperative bleeding, perforation and residual/local recurrence during colonoscopic treatment in Japan. Dig Endosc 2010; 22:376-80.

19. Terasaki M, Tanaka S, Shigita K, et al. Risk factors for delayed bleeding after endoscopic submucosal dissection for colorectal neoplasms. Int J Colorectal Dis 2014; 29:877-82.

20. Akintoye E, Kumar N, Aihara H, Nas H, Thompson CC. Colorectal endoscopic submucosal dissection: a systematic review and meta-analysis. Endosc Int Open 2016; 4:E1030-E1044.

21. Rex DK, Hassan C, Dewitt JM. Colorectal endoscopic submucosal dissection in the United States: why do we hear so much about it and do so little of it? Gastrointest Endosc 2017; 85:554-8.

22. De Ceglie A, Hassan C, Mangiavillano B, et al. Endoscopic mucosal resection and endoscopic submucosal dissection of colorectal lesions: a systematic review. Crit Rev Oncol Hematol 2016; 104:138-55.

23. Oka S, Tanaka S, Saito $Y$, et al. Local recurrence after endoscopic resection for large colorectal neoplasia: a multicenter prospective study in Japan. Am J Gastroenterol 2015; 110:697-707.

24. Lee EJ, Lee JB, Lee SH, et al. Endoscopic submucosal dissection for colorectal tumors-1,000 colorectal ESD cases: one specialized institute's experiences. Surg Endosc 2013; 27:31-9.

25. Sakamoto T, Saito Y, Fukunaga S, Nakajima T, Matsuda T. Learning curve associated with colorectal endoscopic submucosal dissection for endoscopists experienced in gastric endoscopic submucosal dissection. Dis Colon Rectum 2011; 54:1307-12.

26. Chong DH, Poon CM, Leong HT. Colorectal endoscopic submucosal dissection at a low-volume centre: tips and tricks, and learning curve in a district hospital in Hong Kong. Hong Kong Med J 2016; 22:256-62.

27. Ebigbo A, Messmann H. How can we make the learning curve of endoscopic submucosal dissection for (Western) endoscopists less steep? Endoscopy 2016; 48:697-8.

28. Homma K, Otaki Y, Sugawara M, Kobayashi M. Efficacy of novel SB knife Jr examined in a multicenter study on colorectal endoscopic submucosal dissection. Dig Endosc 2012; 24 Suppl 1:117-20.

29. Akahoshi K, Okamoto R, Akahane H, et al. Endoscopic submucosal dissection of early colorectal tumors using a grasping-type scissors forceps: a preliminary clinical study. Endoscopy 2010; 42:419-22.

30. Yamamoto K, Michida T, Nishida T, et al. Colorectal endoscopic submucosal dissection: recent technical advances for safe and successful procedures. World J Gastrointest Endosc 2015; 7:1114-28. 